FSI $($ Russia $)=0.234$

SJIF $($ Morocco $)=\mathbf{2 . 0 3 1}$

SOI: $\underline{1.1 / \text { TAS }}$ DOI: $10.15863 /$ TAS

\section{International Scientific Journal}

\section{Theoretical \& Applied Science}

p-ISSN: 2308-4944 (print) e-ISSN: 2409-0085 (online)

Year: 2017 Issue: 02 Volume: 46

Published: $28.02 .2017 \quad \underline{\text { http://T-Science.org }}$

SECTION 6. Metallurgy and energy.
E.S. Belyaev

Candidate of technical Sciences, associate professor of «Materials science, technology of materials and heat treatment of metals» Nizhny Novgorod State Technical University n.a. R.E. Alekseev

V.K. Sorokin

Doctor of Technical Sciences, Professor of «Materials science, technology of materials and heat treatment of metals»

Nizhny Novgorod State Technical University n.a. R.E. Alekseev

N.V. Makarov

Postgraduate student of the Department «Materials science, technology of materials and heat treatment of metals»

Nizhny Novgorod State Technical University n.a. R.E. Alekseev

M.A. Kravchenko

Master student of the Department «Materials science, technology of materials and heat treatment of metals»

Nizhny Novgorod State Technical University n.a. R.E. Alekseev

\title{
THE INFLUENCE OF MICRO - AND NANO-SIZED DIAMOND FILLERS ON POWDER ROLLING PHYSICAL AND MECHANICAL PROPERTIES
}

Abstract: It is analyzed the influence of micro- and nano-sized diamond filler on the physico-mechanical properties of diamond-containing powder rolling. It was established a strong softening effect of nanodiamond filler on the basis of the softening coefficient $k_{p}=\sigma_{c} / \sigma_{a c}$ with relatively low concentration of conventional $K=40 \%$. Nanodiamond filler strong softening effect conditioned by its metal bond allocation. Limited conditional concentration of nanodiamond filler $K=3,96 \%$ in rolling on the basis of copper powder ПMC-1 is installed by calculation method. Given recommendations about using polycrystalline diamond brand RDDM 0-0,5.

Key words: the powder metallurgy, the diamond-containing rolling, the tensile strength, the softening coefficient, the microstructure of diamond-containing rolling.

Language: Russian

Citation: Belyaev ES, Sorokin VK, Makarov NV, Kravchenko MA(2017) THE INFLUENCE OF MICRO AND NANO-SIZED DIAMOND FILLERS ON POWDER ROLLING PHYSICAL AND MECHANICAL PROPERTIES. ISJ Theoretical \& Applied Science, 02 (46): 155-162.

Soi: http://s-o-i.org/1.1/TAS-02-46-27 Doi: crossef https://dx.doi.org/10.15863/TAS.2017.02.46.27

\section{ВЛИЯНИЕ МИКРО - И НАНОРАЗМЕРНОГО АЛМАЗНОГО НАПОЛНИТЕЛЯ НА ФИЗИКО- МЕХАНИЧЕСКИЕ СВОЙСТВА ПОРОШКОВОГО ПРОКАТА}

Аннотация: Выполнен анализ влияния микро- и наноразмерного алмазного наполнителя на физикомеханические свойства порошкового алмазосодержащего проката. Установлено сильное разупрочняющее действие наноалмазного наполнителя при относительно малой условной концентращии $K=40 \%$ на

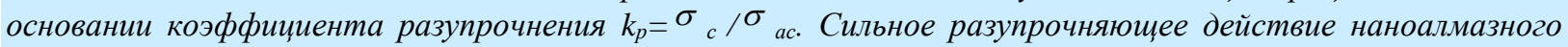
наполнителя обусловлено его распределением в металлической связке. Расчетным способом установлена предельная условная конщентрация наноалмазного наполнителя $K=3,96 \%$ в прокате на основе порошка меди ПМС-1. Даны рекомендации по применению поликристаллических алмазов марки RDDM 0-0,5.

Ключевые слова: порочковая металлургия, алмазосодержащий прокат, предел прочности, коэффициент разупрочнения, микроструктура алмазосодержащего проката. 


\section{Введение}

Развитие промышленности требует разработки новых и совершенствования ранее разработанных материалов. Постоянно возрастают требования к эксплуатационным и технологическим характеристикам материалов. Композиты во многом соответствуют сложившейся тенденции повышения требований к материалам. Свойства композитов формируются по принципу аддитивности в соответствии с долями входящих в состав компонентов, тем самым обеспечивая требуемые свойства. Производство композиционных материалов на металлической матрице обеспечивается технологиями порошковой металлургии [1-6].

Данная работа посвящена изучению порошковых двух объемных композитов с микрои наноразмерным алмазным наполнителем. Ранее выполнены обширные, всесторонние исследования порошковых, листовых, абразивных материалов с микрометрическим алмазным наполнителем для нужд электронной промышленности [1-3]. Алмазные наполнители обладают абразивной способностью и с успехом применяются при изготовлении инструментальных металлоалмазных композиций $[1-3,6,7]$.

Нанометрические алмазы имеют округлую форму частиц, что существенно влияет на их свойства. Синтетические наноразмерные алмазы не обладают режущей способностью и являются твердой смазкой, наличие твердой смазки в порошковом листовом абразивном алмазосодержащем материале позволяет повысить качество разделения компонентов электронной техники, т.е. уменьшить количество сколов и износ инструмента.

В работе проведено обобщение влияния алмазного наполнителя микро- и наноразмерности на прочность листового алмазосодержащего материала на основе оловянно-никелевой бронзы и меди.

\section{Материалы и оборудование}

Алмазосодержащие изготавливались методом металлургии (прокатка + спекание + уплотняющая прокатка) [1, 2]. Прокатка порошковой шихты осуществлялась в прокатном стане дуо с горизонтально расположенными валками. Образцы после прокатки имели пористость $\sim 35 \%$ и различную толщину. После спекания проката его подвергали четырем циклам механо-термической обработке с промежуточными отжигами. Толщина неспеченного порошкового проката выбрана таким образом, чтобы после механо-термической обработки со степенью обжатия $\varepsilon=30 \%$, получить необходимую толщину готового алмазосодержащего проката.

На основе оловянно-никелевой бронзы изготавливались материалы с микрометрическим наполнителем, а на основе порошка меди с нанометрическим. Шихта оловянно-никелевой бронзы содержит 6,5 масс. \% олова и 4,0 масс. \% никеля. При составлении шихты использовались следующие порошки:

- порошок меди ПМС-1, ГОСТ 4960-2009;

- порошок никеля ПНК-УТЗ, ГОСТ 9722-97;

- порошок олова ПО-1, ГОСТ 9723-73;

- порошок синтетических алмазов, ГОСТ 9206-80;

- порошок поликристаллических алмазов, RDDM 0-0,5.

Смешивание шихты на основе оловянноникелевой бронзы и микрометрического алмазного наполнителя проводили в лабораторном баночном смесителе в течение 120 минут. Смешивание шихты, состоящей из порошка меди ПМС-1 и наноалмазного наполнителя марки RUDDM 0-0,5, проводили в шаровой мельнице в течение 10 часов. Частицы наноалмазов в шихте за счет довольно длительного вращения равномерно распределяются по поверхности частиц порошка ПМС-1 (рисунок 1).

В опытах варьировали величиной средней зернистости, условной концентрацией алмазного наполнителя и толщиной проката после всех циклов механо-термической обработки. В таблице 1 приведены уровни варьирования факторами, а также прочность алмазосодержащего проката, прочность связки полученной методом порошковой металлургии и коэффициент разупрочнения. Коэффициент разупрочнения, представленный в таблице 1 , вычисляли по формуле:

$$
k_{p}=\frac{\sigma_{c}}{\sigma_{a c}}
$$

где $\sigma_{c}$ - предел прочности металлической связки (безалмазного порошкового проката);

$\sigma_{a c}$ - предел прочности алмазосодержащего порошкового проката на металлической связке с пределом прочности $\sigma_{c}$.

В общем случае введение неметаллического наполнителя в металлическую связку приводит к снижению прочности материала по сравнению с исходной металлической связкой [1, 9-10]. Коэффициент разупрочнения принят за меру влияния алмазного наполнителя на предел прочности металлической связки. 


\begin{tabular}{|c|c|c|c|c|c|c|}
\hline Impact Factor: & $\begin{array}{l}\text { ISRA (India) } \\
\text { ISI (Dubai, UAF } \\
\text { GIF (Australia) } \\
\text { JIF }\end{array}$ & $\begin{array}{l}=1.344 \\
=0.829 \\
=0.564 \\
=1.500\end{array}$ & $\begin{array}{l}\text { SIS (USA) } \\
\text { PИНЦ (Russia) } \\
\text { ESJI (KZ) } \\
\text { SJIF (Morocco) }\end{array}$ & $\begin{array}{l}=0.912 \\
=0.234 \\
=1.042 \\
=\mathbf{2 . 0 3 1}\end{array}$ & $\begin{array}{l}\text { ICV (Poland) } \\
\text { PIF (India) } \\
\text { IBI (India) }\end{array}$ & $\begin{array}{l}=6.630 \\
=1.940 \\
=4.260\end{array}$ \\
\hline
\end{tabular}

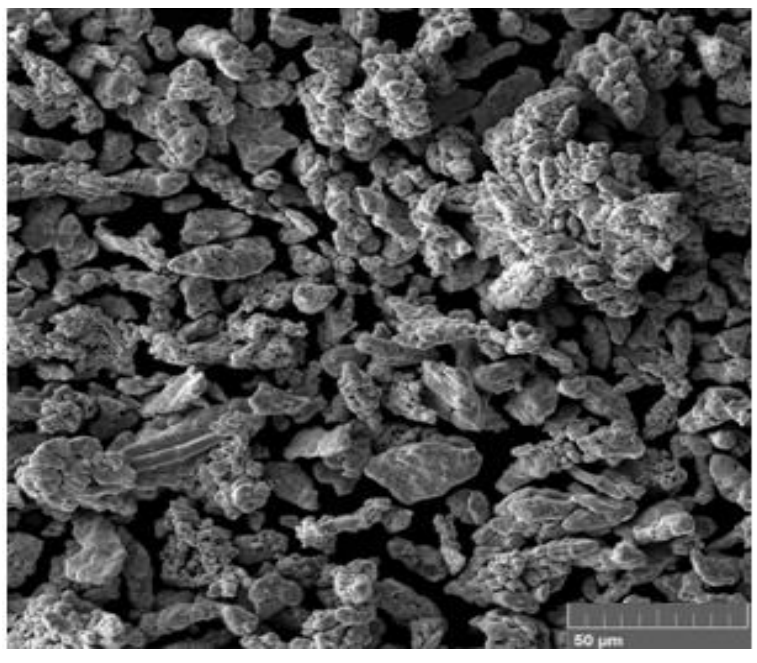

a

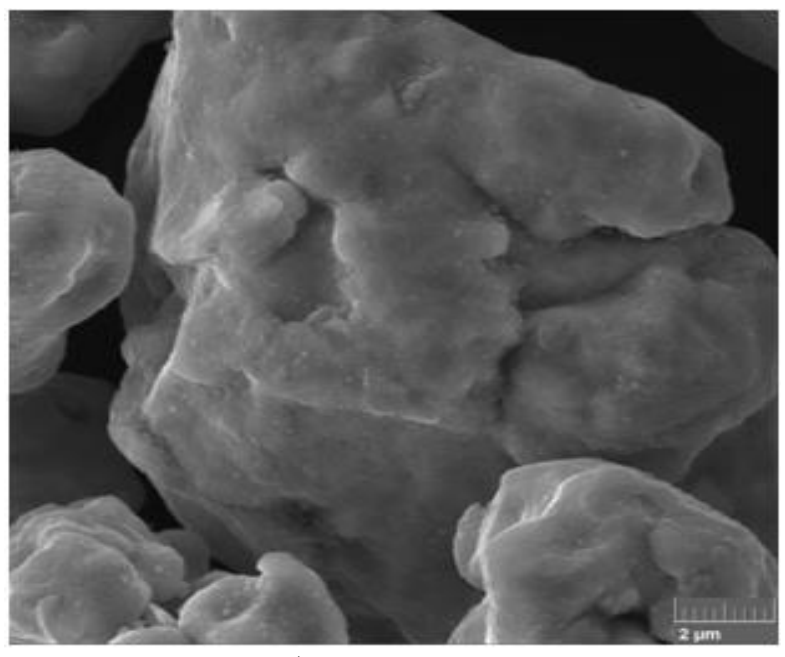

6

а - разрешение 50 мкм, б - разрешение 2 мкм.

Рисунок 1 - Снимки РЭМ шихты с концентрацией 0,8\% наноалмазов.

Таблица 1

Уровни варьирования факторами в натуральном масштабе и результаты экспериментов

\begin{tabular}{|c|c|c|c|c|c|c|}
\hline $\begin{array}{c}\text { № } \\
\text { опыта }\end{array}$ & $\begin{array}{c}\text { Средняя } \\
\text { величина зерна } \\
\text { алмазного } \\
\text { порошка, мкм }\end{array}$ & $\begin{array}{r}\text { Условная } \\
\text { концентрация } \\
\text { алмазного } \\
\text { порошка } K, \% \\
\end{array}$ & $\begin{array}{l}\text { Толщ } \\
\text { ина } \\
\text { ленты, } \\
\text { мкм } \\
\end{array}$ & $\begin{array}{c}\text { Предел } \\
\text { прочности } \\
\sigma_{a c}, \text { МПа }\end{array}$ & $\begin{array}{c}\text { Предел } \\
\text { прочности } \\
\sigma_{c}, \text { МПа }\end{array}$ & $\begin{array}{c}\text { Коэффициент } \\
\text { разупрочнения } \\
k_{p}\end{array}$ \\
\hline & $x_{1}$ & $x_{2}$ & $x_{3}$ & - & - & $y$ \\
\hline 1 & 8 & 50 & 40 & 322,6 & \multirow{12}{*}{735,5} & 2,3 \\
\hline 2 & 16 & 50 & 40 & 264,8 & & 2,8 \\
\hline 3 & 8 & 100 & 40 & 239,3 & & 3,1 \\
\hline 4 & 16 & 100 & 40 & 161,8 & & 4,5 \\
\hline 5 & 8 & 50 & 80 & 449,1 & & 1,6 \\
\hline 6 & 16 & 50 & 80 & 353,0 & & 2,1 \\
\hline 7 & 8 & 100 & 80 & 246,1 & & 3 \\
\hline 8 & 16 & 100 & 80 & 259,9 & & 2,8 \\
\hline 9 & 12 & 75 & 60 & 259,9 & & 2,8 \\
\hline 10 & 12 & 75 & 60 & 274,6 & & 2,7 \\
\hline 11 & 12 & 75 & 60 & 262,8 & & 2,8 \\
\hline 12 & 12 & 75 & 60 & 260,9 & & 2,8 \\
\hline 13 & 0,25 & 40 & 600 & 15,50 & \multirow{3}{*}{352,4} & 22,7 \\
\hline 14 & 0,25 & 24 & 600 & 29,20 & & 12,1 \\
\hline 15 & 0,25 & 8 & 600 & 125,9 & & 2,8 \\
\hline
\end{tabular}

Примечание: Опыты №№1-12 - связка оловянно-никелевая бронза 6,5 масс. \% олова и 4,0 масс. \% никеля; Опыты №№13-15 связка - медь

В таблице 1 нетрудно заметить, что опыты 1-12 представляют собой полный факторный эксперимент по плану $2^{3}$ с четырьмя параллельными опытами на основном уровне. № 13-15 представляют собой одномерные опыты с изменением только концентрации порошка RUDDM 0-0,5 в медной матрице.

\section{Разработка регрессионной модели}

Данные (таблица 1) можно обобщить с помощью полиномиальной квадратичной модели. После выполнения соответствующих расчетов имеем уравнение регрессии: 


\begin{tabular}{|c|c|c|c|c|c|c|}
\hline Impact Factor: & $\begin{array}{l}\text { ISRA (India) } \\
\text { ISI (Dubai, UAF } \\
\text { GIF (Australia) } \\
\text { JIF }\end{array}$ & $\begin{array}{l}=1.344 \\
=0.829 \\
=0.564 \\
=1.500\end{array}$ & $\begin{array}{l}\text { SIS (USA) } \\
\text { PИНЦ (Russia) } \\
\text { ESJI (KZ) } \\
\text { SJIF (Morocco) }\end{array}$ & $\begin{array}{l}=0.912 \\
=0.234 \\
=1.042 \\
=2.031\end{array}$ & $\begin{array}{l}\text { ICV (Poland) } \\
\text { PIF (India) } \\
\text { IBI (India) }\end{array}$ & $\begin{array}{l}=6.630 \\
=1.940 \\
=4.260\end{array}$ \\
\hline
\end{tabular}

$$
y=-3,409-4,684 x_{1}+0,882 x_{2}+0,199 x_{1}{ }^{2}-0,0057 x_{2}{ }^{2}
$$

Все коэффициенты, вошедшие в уравнение регрессии, имеют уровень значимости $p$, вычисленный по критерию Фишера, менее 0,05 . Скорректированный коэффициент детерминации модели $R^{2}=0,98$. Значение остатков по модулю не более 1,452. Остатки хорошо описываются теоретической кривой нормального распределения Гаусса. Нормальновероятностный график остатков и ожидаемых нормальных значений не имеет существенных систематических отклонений от теоретической прямой. Остатки и предсказанные моделью значения распределены бессистемно. Дисперсионный анализ полученного уравнения регрессии в целом показывает уровень значимости $p$ менее 0,05 . Выполненный комплексный статистический анализ свидетельствует о пригодности полученной модели.

На рисунке 2 представлена карта стандартизированных эффектов Парето, наглядно демонстрирующая влияние линейных и квадратичных членов уравнения 1 на значения коэффициента разупрочнения.

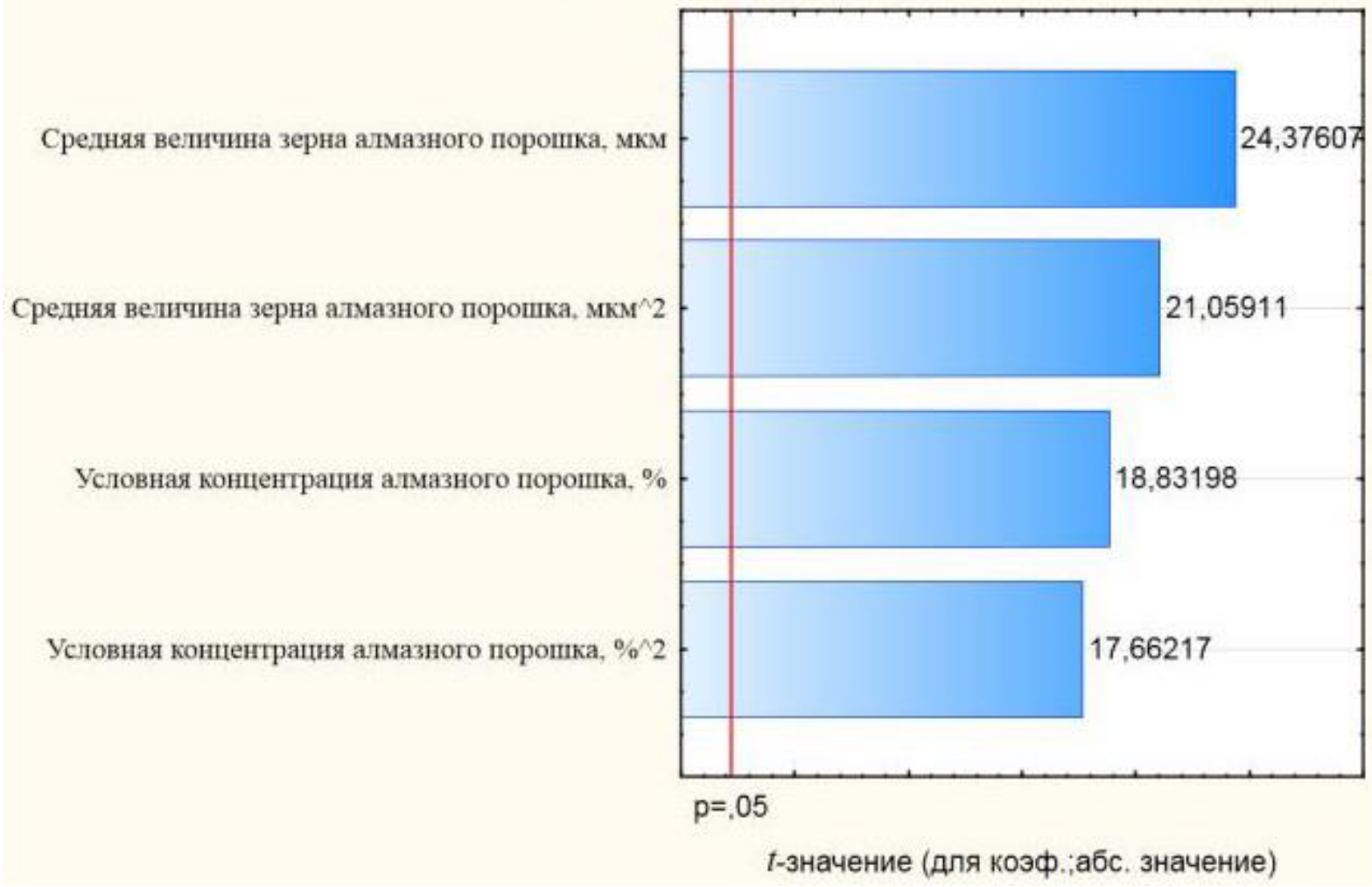

Рисунок 2 - Карта Парето стандартизированных эффектов

\section{Полученные результаты и обсуждение}

Влияние алмазного наполнителя микро- и наноразмерности на коэффициент разупрочнения имеет существенные различия. Так рост средней величины зерна микрометрического алмазного наполнителя от 8 до 16 мкм разупрочняет исходную металлическую связку в $2,8 \ldots . .4,5$ раза при условной концентрации $\mathrm{K}=100 \%$. Нанометрический алмазный наполнитель при условной концентрации $\mathrm{K}=40 \%$ разупрочняет исходную медную связку в 22,7 раза. На рисунке 3 показано изменение коэффициента разупрочнения от средней величины алмазного порошка и его условной концентрации.

Такое сильное влияние наноразмерного алмазного наполнителя по сравнению с микрометрическим объясняется отличиями их распределения в металлической связке (рисунок 4). Микрометрический алмазный наполнитель распределен в связке равномерно, размер зерен наполнителя соизмерим с размером частиц порошка металлической связки (рисунок 3 , а). Нанометрический алмазный наполнитель распределяется по границам исходных частиц порошка (агрегатная структура дисперсноупрочненного материала), что изолирует частицы порошка металлической связки во время спекания [8].

Расчетным методом можно оценить изолирующее действие наноалмазного наполнителя на частицы медной металлической связки, сравнивая средние размеры зерна порошка меди и наноалмазов. Для реализации расчета были приняты допущения: частицы в 


\begin{tabular}{l|lr|ll|ll} 
& ISRA (India) & $=\mathbf{1 . 3 4 4}$ & SIS (USA) & $=\mathbf{0 . 9 1 2}$ & ICV (Poland) & $=\mathbf{6 . 6 3 0}$ \\
Impact Factor: & ISI (Dubai, UAE) $=\mathbf{0 . 8 2 9}$ & PUHI (Russia) & $=\mathbf{0 . 2 3 4}$ & PIF (India) & $=\mathbf{1 . 9 4 0}$ \\
& GIF (Australia) & $=\mathbf{0 . 5 6 4}$ & ESJI (KZ) & $=\mathbf{1 . 0 4 2}$ & IBI (India) & $\mathbf{4 . 2 6 0}$ \\
& JIF & $\mathbf{1 . 5 0 0}$ & SJIF (Morocco) & $\mathbf{2 . 0 3 1}$ & & \\
\hline
\end{tabular}

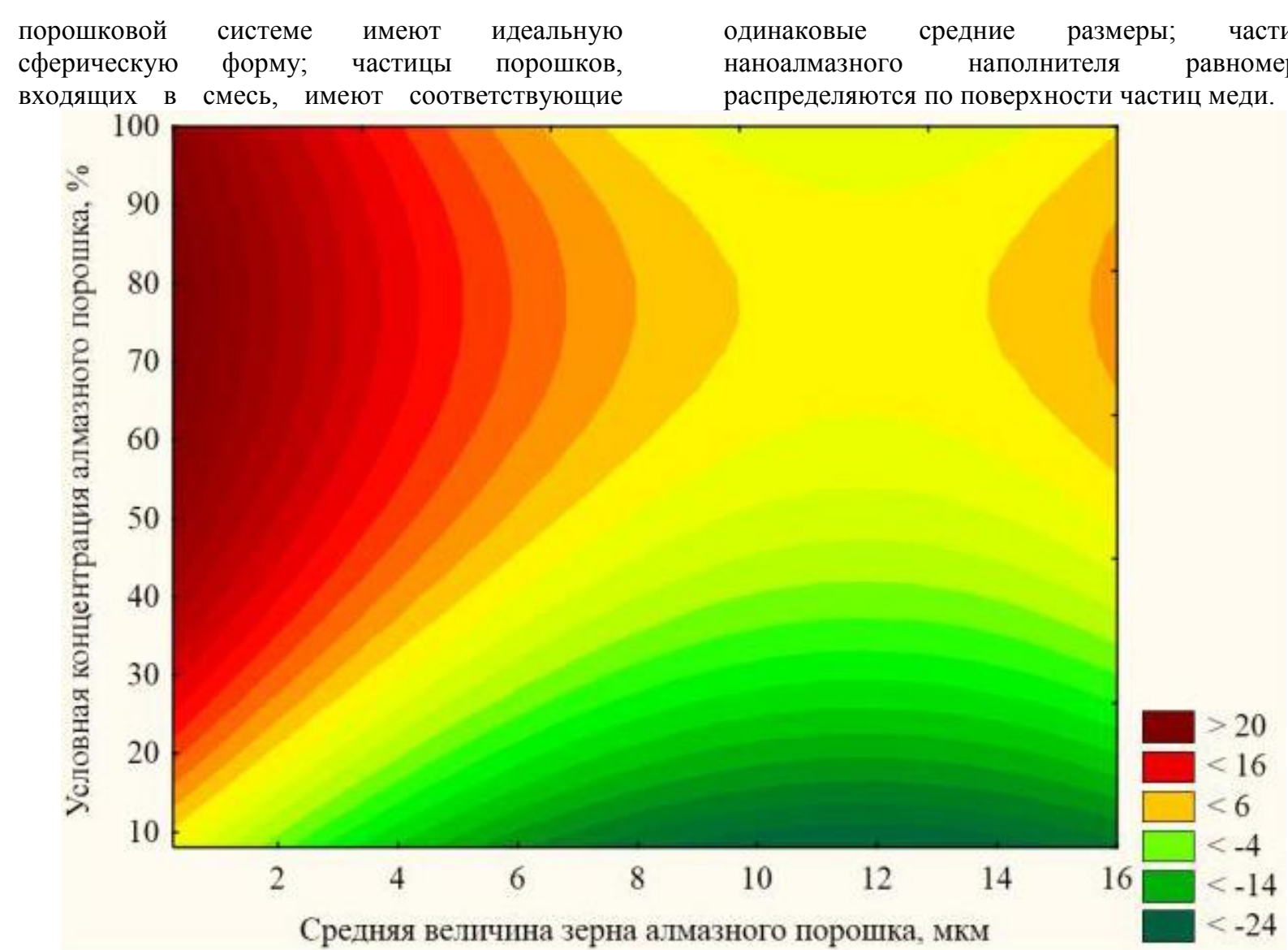

Рисунок 3 - Зависимость коэффициента разупрочнения от условной концентрации и средней величины зерна алмазного порошка.

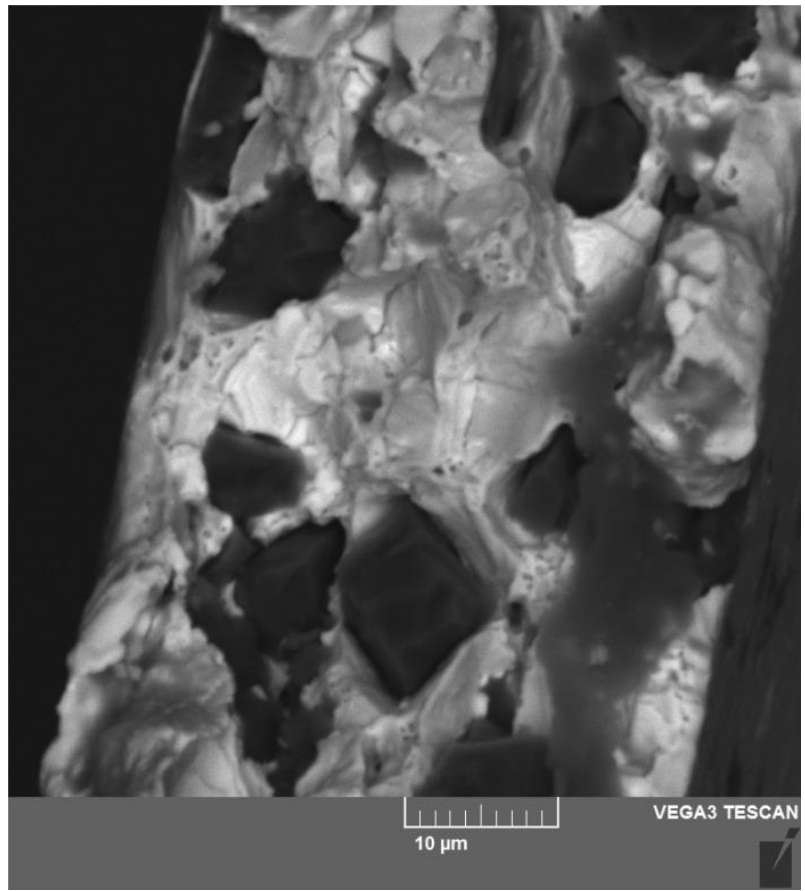

a)

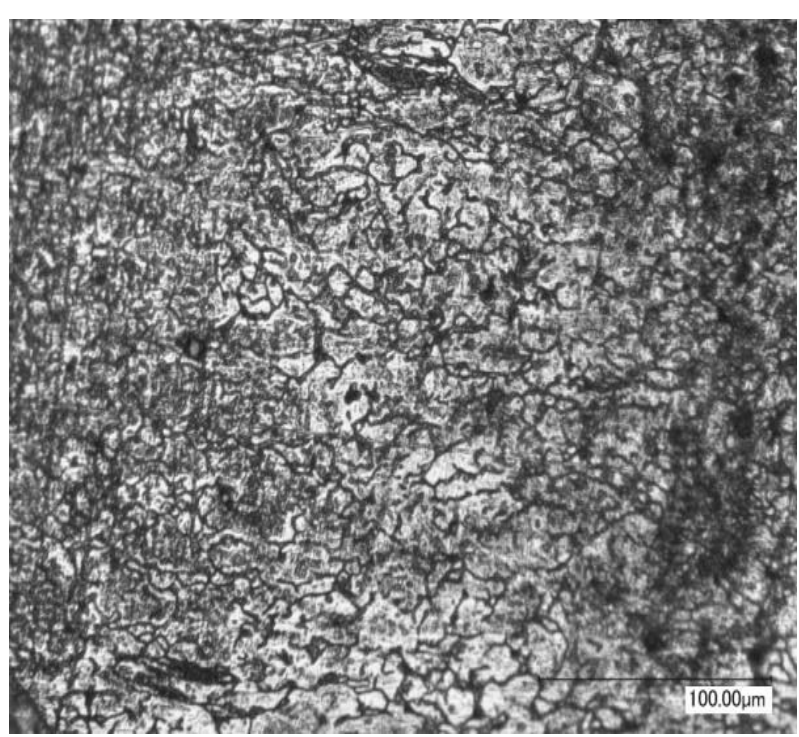

б)

$\mathrm{a}-\mathrm{K}=100 \% ;$ б - K=10\%

Рисунок 4 - Микроструктура алмазосодержащего материала с микрометрическим (а) и нанометрическим (б) алмазным наполнителем

ISPC Technology and science,

Philadelphia, USA 


\begin{tabular}{|c|c|c|c|c|c|c|}
\hline Impact Factor: & $\begin{array}{l}\text { ISRA (India) } \\
\text { ISI (Dubai, UAE } \\
\text { GIF (Australia) } \\
\text { JIF }\end{array}$ & $\begin{array}{l}=1.344 \\
=0.829 \\
=0.564 \\
=1.500\end{array}$ & $\begin{array}{l}\text { SIS (USA) } \\
\text { PИНЦ (Russia } \\
\text { ESJI (KZ) } \\
\text { SJIF (Morocco }\end{array}$ & $\begin{array}{r}=\mathbf{0 . 9 1 2} \\
=\mathbf{0 . 2 3 4} \\
=\mathbf{1 . 0 4 2} \\
=\mathbf{2 . 0 3 1}\end{array}$ & $\begin{array}{l}\text { ICV (Poland) } \\
\text { PIF (India) } \\
\text { IBI (India) }\end{array}$ & $\begin{array}{l}=6.630 \\
=1.940 \\
=4.260\end{array}$ \\
\hline
\end{tabular}

Соответственно частица меди - шар $d=100$ мкм, частица наноалмазного наполнителя - шар $d=0,25$ мкм. Количество наноразмерных частиц

$$
N=\frac{4 D_{C u}^{2}}{D_{H . A .}^{2}}
$$

где $D_{C u}$ - средний диаметр частиц порошка меди, мкм;

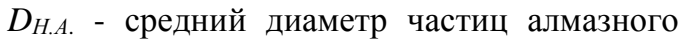
порошка, мкм.

Подставив средний диаметр частиц порошка меди и наноалмазов, получаем значение $N=640000$, т.е. на одну частицы порошка меди приходиться 640000 частиц порошка наноалмазов при равномерном однослойном покрытии частицы меди наноалмазами. В идеальных алмазного наполнителя, покрывающие частицу меди равномерно в один слой, можно рассчитать по формуле:

$$
\text { об.\%H.A. }=\frac{640000 \cdot D_{H . A .}^{3} \cdot 100 \%}{D_{C u}^{3}+640000 \cdot D_{H . A .}^{3}}=0,99 \%
$$

условиях при $N=640000$ во время спекания образование металлической связи между частицами порошка меди разделенных слоем наноалмазов толщиной $h=2 \cdot 0,25=0,5 \quad$ мкм маловероятно.

Рассчитаем объемное процентное содержание наноалмазов в медной связке при соотношении частиц меди и наноамазного порошка 1:640000:
Объемное содержание наноалмазного порошка можно перевести в условную концентрацию $K_{P}(K=100 \%$ соответствует 25 об. \%) в соответствии с пропорцией:

$$
K_{P}=\frac{o \sigma . \% H \cdot A \cdot 100 \%}{25 \%}=3,96 \%
$$

Объемное содержание наноалмазного порошка также можно перевести в массовое:

$$
\text { масс. } \% \text { H.A. }=\frac{\text { об.\%H.A. } \cdot \rho_{H . A .} \cdot 100 \%}{\text { об.\%H.A. } \cdot \rho_{\text {H.A. }}+(100-\text { oб.\%H.A. }) \cdot \rho_{C u}}=0,39 \%
$$

где $D_{C u}$ - средний диаметр частиц порошка меди, мкм;

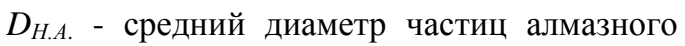
порошка, мкм.

В таблице 2 приведены данные, связывающие условную концентрацию наноалмазного наполнителя в порошковом прокате на основе меди, расчетную условную концентрацию, при которой образование металлической связи при спекании между частицами медного порошка маловероятно, и предел прочности.

Таблица 2

\section{Условная концентрация наноалмазного наполнителя и предел прочности проката}

\begin{tabular}{|c|c|c|c|}
\hline $\begin{array}{c}\text { Условная концентрация } \\
\text { наноалмазного } \\
\text { наполнителя } K, \%\end{array}$ & $\begin{array}{c}\text { Расчетная концентрация } \\
\text { наноалмазного } \\
\text { наполнителя } K_{P}, \%\end{array}$ & $K / K_{P}$ & $\begin{array}{c}\text { Предел прочности проката с } \\
\text { наноалмазным наполнителем } \sigma_{B}, \\
\text { МПа }\end{array}$ \\
\hline 8 & \multirow{2}{*}{3,96} & 2,020 & 125,9 \\
\hline 24 & & 6,061 & 29,20 \\
\hline 40 & & 10,10 & 15,50 \\
\hline
\end{tabular}


Отношение $K / K_{P}$ (таблица 2) характеризует степень изоляции частиц меди, распределенным по поверхности наноалмазным наполнителем, с ростом отношения степень изолированности повышается, а прочность проката существенно снижается.

Судя по значениям $K / K_{P}$ (таблица 2) металлическая связь в прокате всех рассматриваемых условных концентраций образовываться не должна. Однако коэффициент разупрочнения, полученный в опыте №15 (таблица 1) соизмерим с коэффициентом разупрочнения при использовании алмазного наполнителя микрометрического размера с условной концентрации $K=100 \%$.

Очевидно, в процессе уплотняющей прокатки происходит сдвиг покрытых наноалмазным наполнителем частиц меди относительно друг друга, что приводит к нарушению целостности слоя наноалмазов у соседних частиц меди и образованию в процессе отжига металлической связи.

Также следует учитывать допущения, сделанные при расчете $K_{P}$. Частицы порока меди по своей форме существенно отличаются от идеальной сферической, при смешивании, возможно, не достигнуть равномерности покрытия частиц меди наноалмазами и покрытия всех входящих в порошковую систему частиц меди.

Для сравнения по формулам 3-5 рассчитаем условную концентрацию $K_{P}$ для микрометрического алмазного наполнителя с $d=16$ мкм, имеем $K_{P}=156 \%$, т.е. отношение $K / K_{P}$ в опытах №1-12 (таблица 1) менее 1 и максимальное значение коэффициента разупрочнения составляет $k_{p}=4,5$ (опыт №4).

\section{Выводы.}

Влияние нано- и микрометрического алмазного наполнителя на прочность металлической матрицы имеет существенные различия, связанные с распределением частиц наполнителя в матрице.

Предложена методика оценки коэффициента разупрочнения металлической матрицы на основании расчетного значения условной концентрации алмазного наполнителя $K_{P}$. Для получения достаточно высоких прочностных свойств алмазосодержащего проката необходимо, чтобы отношение условной $K$ и расчетной условной концентрации $K_{P}$ алмазного наполнителя было менее 1. В этом случае образование металлической связи между частицами связки в процессе спекания и механотермической обработки весьма вероятно.

В свою очередь $K_{P}$ рассчитывается на основании геометрического сравнения частиц металлических и неметаллических порошков, входящих в шихту. При расчете $K_{P}$ приняты допущения: частицы в порошковой системе имеют идеальную сферическую форму; частицы порошков, входящих в смесь, имеют соответствующие одинаковые средние размеры; частицы наноалмазного наполнителя равномерно распределяются по поверхности частиц меди.

Проведенные исследования позволяют рекомендовать применение наноалмазного наполнителя в условной концентрации $K$ менее 8\% при использовании порошка меди ПМС-1 ГОСТ 4960-75 в качестве основы шихты и порошка поликристаллических алмазов RUDDM 0-0,5 в качестве наполнителя. При увеличении условной концентрации наноалмазов происходит существенное снижение прочности алмазосодержащего проката.

Путь повышения прочности наноалмазного проката на основе медной металлической связки снижение дисперсности частиц порошка меди в комплексе с высокоэнергетическим смешиванием шихты. Такой подход позволит уменьшить величину $K / K_{P}$ и изменить агрегатную структуру материала на дисперсную.

\section{References:}

1. (2011) Tehnologiya izgotovleniya i oborudovanie po proizvodstvu poroshkovyih i kompozitsionnyih materialov i izdeliy: ucheb. posobie / V.K. Sorokin, L.S. Shmelev - NGTU im. R.E. Alekseeva. Nizhniy Novgorod, 2011. $184 \mathrm{p}$.

2. (2002) Proizvodstvo poroshkovogo prokata / Pod red. V. K. Sorokina. - M.: ZAO «Metallurgizdat», 2002. - 296 p.
3. Sorokin VK (2001) Osobennosti almazosoderzhaschih smesey poroshkov i spechennyih plastin / V. K. Sorokin, L. S. Shmelev // Metallurgiya. - 2001. - \# 11. - p. 53-54.

4. (1980) Kompozitsionnyie spechennyie antifriktsionnyie materialyi / Fedorchenko I.M., Pugina L.I. - Kiev: Nauk. dumka, 1980. - 404 p.

5. (1985) Poroshkovaya metallurgiya. Materialyi, tehnologiya, svoystva, oblasti primeneniya 


\begin{tabular}{|c|c|c|c|c|c|c|}
\hline Impact Factor: & $\begin{array}{l}\text { ISRA (India) } \\
\text { ISI (Dubai, UAE } \\
\text { GIF (Australia) } \\
\text { JIF }\end{array}$ & $\begin{array}{l}=1.344 \\
=0.829 \\
=0.564 \\
=1.500\end{array}$ & $\begin{array}{l}\text { SIS (USA) } \\
\text { PИНЦ (Russia) } \\
\text { ESJI (KZ) } \\
\text { SJIF (Morocco) }\end{array}$ & $\begin{array}{l}=0.912 \\
=0.234 \\
=1.042 \\
=\mathbf{2 . 0 3 1}\end{array}$ & $\begin{array}{l}\text { ICV (Poland) } \\
\text { PIF (India) } \\
\text { IBI (India) }\end{array}$ & $\begin{array}{l}=6.630 \\
=1.940 \\
=4.260\end{array}$ \\
\hline
\end{tabular}

Spravochnik / I.M. Fedorchenko, I.N. Frantsevich, I.D. Radomyiselskiy i dr.; Otv. red. I.M. Fedorchenko. - Kiev: Nauk. dumka, 1985. - $624 \mathrm{p}$.

6. Belyaev ES (2013) Almazosoderzhaschie materialyi dlya otreznogo instrumenta na osnove zheleznogo poroshka/T.M. Kolosova, V.K. Sorokin, S.V. Kostromin // Sovremennyie problemyi nauki i obrazovaniya. - 2013. - , \#. 2. - p. 209-217.

7. (1990) Almazyi i sverhtverdyie materialyi / V. P. Polyakov, A. V. Nozhkin, N. V. Chirikov: Uchebnoe posobie dlya vuzov. - M.: Metallurgiya, 1990. - 327 p.
8. Libensov GA (1990) Proizvodstvo poroshkovyih izdeliy - M.:Izdatelstvo «Metallurgiya», 1990.- $237 \mathrm{p}$

9. Belyaev ES (2015) Struktura i svoystva metallosteklyannyih materialov na osnove poroshka karbonilnogo zheleza / Kolosova T.M., Alekseev V.A., Makarov N.V., Getmanovskij Yu.A.// Fundamentalnyie issledovaniya. - 2015. - \# 4. - p. 22-27

10. Belyaev ES (2017) Vliyanie soderzhaniya ugleroda i stekla na tverdost metallosteklyannyih materialov / Makarov N.V., Getmanovskij Yu.A.// Theoretical \& Applied Science. 2017. \# 01 (45). p. 160-166. 